\title{
What do we Know about Girls in the Care and Criminal Justice Systems?
}

\section{Abstract}

Purpose:

This article highlights the neglect of girls in care who come into conflict with the law, arguing that a gender-neutral approach in this area risks further marginalising an already vulnerable population. Approach:

A critical review of the literature and current policy climate is undertaken to explore what is known about the experiences of females in the justice system, as well as knowledge gaps.

Findings:

Evidence on the prevalence and nature of offending by girls in care is limited. However, as looked after children, girls may be more likely to have their own behaviour unnecessarily criminalised. Whilst females and males share some prior experiences of victimisation and trauma, girls also have distinct needs and may be assessed and managed by state care and control systems in very different ways.

\section{$\underline{\text { Research limitations }}$}

The article is not based on primary research and does not present a systematic review of the literature.

\section{Practical implications}

The need to listen to girls and young women, and a far greater recognition of backgrounds of trauma must underpin future policy and practice. Diversion from the formal criminal justice system wherever possible is also a key goal to aspire to.

Originality/Value:

This article focuses on the specific experiences of females. It calls for a gender-sensitive, traumainformed approach to working with girls and women from the care system who come into conflict 
with the law, and questions the value of criminalising those whom the state previously deemed to be in need of welfare and support. 
The numbers of children looked after in England has risen steadily over the last eight years, with 70,440 children in care at 31st March 2016, 44\% of whom were female (Department for Education (DfE), 2016a). Official figures also reveal an increase in the number and proportion of older children in care, with $62 \%$ of children looked after aged 10 years and over in 2016 compared with $56 \%$ in 2012 (DfE, 2016a). The increases in the numbers of those both in care, and over the age of criminal responsibility, make debates about disrupting the care-crime connection particularly pertinent. However, whilst the care-crime connection has traditionally been neglected in research, there has arguably been a particular research silence on females in care who come into conflict with the law.

The Laming Review 'In Care, Out of Trouble' (Prison Reform Trust (PRT), 2016a), and the systematic review of literature to accompany it (Staines, 2016) recently highlighted that girls in care form a minority group within the criminal justice system, and as such "there is a lack of research about their experiences, needs and characteristics" (PRT, 2016a: 72). This situation parallels the relative neglect of all females in the justice system (cf Sharpe, 2012). Thus a focus on the particular needs of females in care is recommended (PRT, 2016a).

This article seeks to contribute towards that effort by considering the current policy climate as well as what is known about the backgrounds of females in care and the criminal justice system. It is frustrating that there is much that we do not know in relation to having an up-to-date national picture of the offences that young women in care are convicted of, and the frequency with which this occurs. Similarly, the true extent of the criminalisation of all children in care is unknown (Howard League, 2017). Whilst our current knowledge-base is limited, this paper considers some of the evidence that does exist in order to highlight some important themes, including perceptions of girls in care, as well as the experiences of women in prison. Following recent work on the general links between trauma and offending (Beyond Youth Custody, 2016), this paper calls for a trauma- 
informed approach (cf. Mendes et al, 2014) to supporting females in the care and criminal justice systems.

\section{Setting the scene}

The discussion below draws predominantly on peer-reviewed journal articles, as well as academic books, government data, policy documents and independent reviews. However, it does not present a systematic review of the literature, and in the space available the choice of sources has inevitably been selective. Whilst most sources relate to the UK, relevant material from other jurisdictions is also considered, highlighting the wider global relevance of the issues. The majority of literature was published in the last 10 years. In exploring the relevance of a trauma-informed approach for females in care who come into conflict with the law, a decision was made to focus particularly on evidence that addressed the following themes: females in care and/or the criminal justice system, the general care-crime connection, and the links between trauma and offending.

As noted by Beyond Youth Custody (BYC) (2016:5), "trauma is a phenomenon that requires both a particular kind of event and a particular kind of reaction to that event - as such, it defies simple definition". However, the definition offered by the Substance Abuse and Mental Health Services Administration (SAMHSA) (2014) highlights that trauma is the sum of the event, the experience and the effect. "Individual trauma results from an event, series of events or set of circumstances that is experienced by an individual as physically or emotionally harmful or threatening and that has lasting adverse effects on the individual's functioning and physical, social, emotional, or spiritual wellbeing" (SAMHSA, 2014 - cited in BYC, 2016).

A number of events typically referred to in the literature as having the potential to generate trauma are also events that, either alone or in combination, may be associated with entry to the care system. These include: emotional, physical and sexual abuse; neglect, witnessing family violence; 
serious injuries; loss of loved ones; abandonment and separation (cf. BYC, 2016). Interestingly, Mendes et al (2014) have argued in their research that offending behaviour by those in care ought to be viewed as a trauma-related outcome.

\section{Offending rates and knowledge gaps}

According to official statistics, looked after children in England are five times more likely to offend than all children, with males twice as likely to offend as females. Three per cent of females in care ( $n=450)$ were convicted or subject to a final warning or reprimand in the year ending 31 March 2016, compared to $6 \%$ of males (DfE, 2016a). Whilst these numbers appear relatively small, the data is very limited because it is based only on those looked after continuously for 12 months or more. Furthermore, as the Howard League (2017) have noted with respect to the criminalisation of children in residential care, "inadequacies in record keeping and data collection mean that we do not have an accurate picture of the extent and nature of the problem" (2017:3). For example, each police force has its own recording system and search capabilities, and there are no identifiers on most police systems for marking an incident as having occurred at a children's home. Meanwhile, children's homes are not required by local authorities or Ofsted to record and report on each callout to the police (Howard League, 2017).

Improvements in national data collection and recording are urgently required. What is more, in order to achieve multi-agency co-operation with respect to reducing the unnecessary criminalisation of children in care (cf. PRT, 2016a), then clearly all agencies need to be not only routinely collecting relevant data, but also recording it in comparable formats (Howard League, 2017).

It is recognised that different types of care placement, such as kinship care and foster care, will potentially impact on children in different ways (cf Wilkinson \& Bowyer, 2017). Indeed, earlier 
research highlights the potential of secure and stable foster placements to divert young women in particular from involvement in the youth justice system (Taylor, 2006) - a clear indication that the care-crime connection is far more complex than assuming that going into care will inevitably lead to justice-system involvement. Nevertheless, this article's focus is predominantly on residential care experiences given that this is where current concerns about system failings have been particularly evident.

\section{The current policy climate}

In considering the current policy climate, an examination of recent policy documents is instructive in highlighting the relative invisibility of females. For example, the South East Protocol on reducing the offending and criminalisation of children in care (2014) has been rightly recognised as an example of good practice in diverting children in care away from the justice system. Yet it is noteworthy that this document has nothing to say about the specific needs of girls. The same is true of the National Police Chief's Council (NPCC) (2015) strategy for policing children and young people which identified avoiding the criminalisation of looked after children as a key priority. Meanwhile, the Taylor Review (2016) of the youth justice system is a far more substantial document, which importantly flags up some of the particular challenges facing looked after children but devotes very little space to girls (aside from brief comments on females in police custody and secure schools).

None of this discussion is meant to suggest that the needs of males are not important. However, it has long been recognised that a gender-neutral approach to youth justice ultimately risks neglecting the specific needs of girls, and discriminating against them, in a system designed for the male majority (All Party Parliamentary Group on Women in the Penal System (APPG) 2012). When combined with the individual-blaming explanations that tend to dominant in official explanations of the care-crime connection, this becomes particularly concerning. 
Many of the so-called 'risk factors' associated with admission to care (e.g. early family disruption) are also factors associated with offending behaviour and as a result of this, it has often been wrongly assumed that children in care are inevitably more likely to commit offences. Yet there is nothing inevitable about this. However, the predominance of risk as the focus of contemporary criminal justice practice has served to perpetuate and legitimise a care-less approach to those with care experience (Fitzpatrick \& Williams, 2017). Whilst pre-care experiences must not be ignored, the focus on risk factors has encouraged an overwhelming emphasis on individual-level explanations in examining the link between care and criminal careers, whereby the focus of blame is directly located with the individual in care and their families (cf. Stanley, 2017). On their own, such explanations are lazy, one-sided and partial. Furthermore, they enable the state in its role of corporate parent to deny or minimise the existence of structural problems and system-level failings, such as the unnecessary criminalisation of minor offences in some care homes (House of Commons Justice Committee, 2013).

Because children in care are under far greater official surveillance than their peers, what is viewed as challenging behaviour may be far more likely to be recorded and come to official attention quickly, in a way which would not be the case for many children living at home with their birth families. This can mean that children in care are at greater risk of coming into contact with the criminal justice system at an early age, which increases the likelihood that they will have further contact at a later date (McAra \& McVie, 2007). Whilst an unprecedented amount of evidence on the general carecrime connection has been produced recently, there is a danger that some reports (e.g. Narey, 2016), and the government's response to them, undermine wider efforts (e.g. Prison Reform Trust, 2016a) to ensure this issue is on the agenda. The government's recent response to Sir Martin's Narey's Review of Children's Residential Care is particularly concerning in this respect. 
“We welcome Sir Martin's recognition that children's homes, on the whole, have worked to address previous problems of over-criminalisation of children in their care, where children's home staff would unnecessarily involve the police in minor incidents. We also welcome his view that the fact that children in homes are more likely to be subject to criminal proceedings is a reflection of the challenges this group face, including their experiences prior to becoming looked after, rather than an indication of the quality of care they receive" (DfE, 2016b, emphasis added).

In the quote above, any potential systemic problems in explaining the care-crime connection are neatly side-stepped, and replaced by a focus on the problems within the individual and their families. Yet research is clear that system-level failings continue. While policy and practice guidance encourages only sparing use of police contact to deal with challenging behaviour, Shaw (2016: 157) found that "the youth justice system is in fact viewed by many practitioners as a useful and necessary adjunct to the care system". Meanwhile, the Howard League's report (2016) on 'Criminal Care' observed that 'Looked after' children living in children's homes are being criminalised at excessively high rates compared to all other groups of children, including those in other types of care" (2016:1). The report further notes that these problems are widely recognised by the government and other relevant authorities, but are not being addressed. There is clearly a conflict of evidence here, Paradoxically, at the same time the government is welcoming the view that overcriminalisation in children's homes has, "on the whole" been dealt with, the Howard League (2017) launches a two year programme of research to end the criminalisation of children in residential care - an indication that, for some at least, this is a problem that persists.

\section{The needs of females in care}


So what are the distinct needs of females? We know that the majority of children enter care in England principally due to abuse and neglect (60\% in 2016), although a mere $2 \%$ enter because of their own socially unacceptable behaviour (DfE, 2016a). The national data is not disaggregated by gender, and is also limited by the fact that it does not distinguish between the various different forms of abuse or neglect. However, it does highlight the clear vulnerability of many of those in care, and the fact that they are more likely to be victims of an offence (in that many will have experienced child abuse in some form), rather than offenders. Recent official data also includes figures on motherhood - reflecting wider concerns about teenage pregnancy and the fact that girls in care are particularly viewed as 'at risk' of this (Slawson, 2016). Of the 15,340 females in care over the age of 12 in March 2016, 2\% were mothers ( $n=270$ ) (DfE, 2016a). Whilst a breakdown of this data by age would be informative, this is not provided in the national data summary.

In addition to the distinct physical and emotional needs and experiences that may be associated with pregnancy/motherhood or indeed losing a child, there are other important gender differences between girls and boys. With respect to children in residential care, O'Neill (2008) argues that girls and boys have different patterns of help seeking and different responses to services. In particular, she notes that girls are more likely than boys to enter care because of problems with family relationships (e.g. abuse and violence at home) and because of concerns about their 'moral' welfare as well as health issues relating to drug and alcohol use (2008: 96). In a recent literature review, Staines (2016) found evidence to suggest that looked after girls may have experienced more difficulties prior to placement (for example, being more likely to have been physically and sexually abused, to have self-harmed or attempted suicide and to have a greater number of background adversities).

Meanwhile, a study of 53 young people in residential care in Canada (Collin-Vezina et al, 2011) identified high levels of trauma experiences and early maltreatment amongst males and females, 
with a majority experiencing emotional abuse (68\%), physical abuse $(60 \%)$ or emotional neglect (58\%). Girls and boys were equally likely to have experienced multiple forms of maltreatment, but girls were far more likely to report sexual abuse $(63 \%)$ in contrast to boys (17\%). Girls were also more likely to report clinical levels of posttraumatic stress symptoms.

Females and males appear to share some of the same experiences of trauma, although there are also important differences, and questions about how individuals and systems respond to that trauma. Maltreatment has been consistently linked to later delinquent behaviour, but evidence suggests that girls appear to react differently than boys to such experiences. Postlethwait and colleagues (2010) noted that "maltreated girls are at greater risk of delinquency than nonmaltreated girls, more so than maltreated versus non-maltreated males. Child welfare-involved girls appear to "catch-up" somewhat with males in their levels of delinquent behaviour" (2010:319).

Similarly, Jonson-Reid and Barth (2000) found in the United States, females within the child welfare system faced particularly high levels of risk for adolescent incarceration when compared to females in the general population. As they note, there are gaps in our understanding of how males and females differ in their response to maltreatment and differ in their response to care experiences. However, we should add to this that there is also a difference in the way that state care and control systems respond to vulnerable females, particularly in the way that they are assessed, managed and controlled. O'Neill (2001) found in her study of secure accommodation that most of the boys, who form the majority of children locked up, were admitted through the criminal justice system. By contrast, the majority of girls were admitted through the welfare system; for example, due to selfharming. She argues that this makes the whole 'care versus control' debate a gendered issue whereby girls in particular may end up receiving more control and punishment than they deserve.

\section{Perceptions of girls in care: a reclassification of needs as risks?}


As O'Neill (2008) has more recently observed, “( $\mathrm{t}$ )here are....striking differences between girls and boys in the assessment of 'risk' and what is judged by social workers and the courts to constitute 'significant harm'...These differences are much more likely to result in heavy interventionist responses with girls than with boys" (2008:96). Meanwhile, Staines (2016: 8) highlights that a reluctance amongst some foster carers and residential care staff to work with girls has been identified in some studies due to fear of allegations of abuse and gendered stereotypes about girls' challenging behaviour. This is also reflected in the wider youth justice workforce. In Baines and Adler's (1994) research, female victims of sexual abuse were variously described by juvenile justice professionals as "manipulative", "hysterical" and "difficult to engage" (1994: 482). Related to this, recent sexual exploitation scandals in the UK (cf. Jay, 2014) have highlighted how young women from "chaotic" backgrounds including those from the care system may be less likely to be perceived as genuine victims.

In her inquiry into child sexual exploitation (CSE) in Rotherham, Alexis Jay described how "children's social care managers seemed reluctant to accept the extent of the problem of CSE within the Borough" (2014: 104). Furthermore, concerns were raised that some referrals made to children's social care were being reclassified as 'Teenager out of control' (2015: 104). Reference was also made to a previous report highlighting that " $(t)$ he young women concerned were often seen by the Police as being deviant or promiscuous. The adult men with whom they were found were not questioned" (Jay, 2014: 85). Jay's inquiry clearly highlights the scandal of vulnerable young women not being listened to, which ultimately results in their experiences of sexual violence and victimisation being ignored. Similarly, the Laming review (PRT, 2016a) received evidence to suggest that girls in care are at greater risk of child sexual exploitation than boys and that this is linked to criminalisation. 
Paradoxically, as looked after children, girls may be more likely to have their own behaviour unnecessarily criminalised. McFarlane's (2010) work on young women in care in New South Wales found that half were facing the Children's Court for property damage offences committed in state care, with police called for incidents such as "putting several small holes in the wall" (McFarlane, 2010:348). Yet girls in particular may find their welfare needs frequently reclassified as risks in a riskdominated criminal justice system; for example, being treated more harshly by magistrates if their behaviour contradicts gender stereotypes (APPG, 2012), and with magistrates assuming that girls without a familial safety net are safer in custody (Stanley, 2017). As Stanley has observed in New Zealand (2017), in such cases, detention occurs on welfare grounds, and "girls and ethnic minority children are more likely to be placed into detention in these circumstances" (2017:60). Not only are there overlapping layers of discrimination with respect to gender and care status, but ethnic identify adds an additional layer of complexity, little explored to date.

\section{How are females from care dealt with as offenders?}

O'Neill (2008) notes that the failure to recognise that alternative approaches and policies may be needed to respond to the distinct needs of girls "has compounded the marginalisation of already socially excluded girls in institutional care, who are expected to 'fit into' provision primarily designed for boys, resulting in even worse outcomes for girls than for their male peers" (2008: 102). Meanwhile, a joint criminal justice inspection led by Her Majesty's Inspectorate of Probation (HMIP) (2014) on all girls in the criminal justice system noted that where promising gender-sensitive approaches had been developed, this tended to be due to the commitment of individuals rather than through any nationally or locally led drive to recognise and prioritise girls' needs.

Worryingly, the HMIP (2014) report noted particular concerns about looked after girls, observing "a pattern of reoffending for girls who were Looked After by local authorities, many who were also 
extremely vulnerable" (2014:4). In addition: "It was particularly concerning that, for those girls who had been 'Looked After' by the local authority before their sentence, links with their social workers were often weak. In such cases, local authorities were failing to meet their legal duties" (HMIP, 2014:9). This fits with wider evidence on the neglected needs of care leavers in the criminal justice system (Fitzpatrick \& Williams, 2017), and their effective abandonment by some local authorities once in prison custody (cf. Fitzpatrick et al, 2016).

Although the HMIP report (2014) identified that the range of interventions available to girls was variable in terms of quality, some critical characteristics were identified that were likely to make the programmes that did exist more successful. These included: ensuring that girls felt safe both physically and emotionally, developing strengths-based approaches and, crucially, recognising past victimisation and trauma. Indeed, as Mendes et al (2014) have argued in their research in Victoria (Australia), offending behaviour by those in care ought to be viewed as a trauma-related outcome.

That said, there are challenges here for practitioners in identifying and evidencing past trauma. In terms of data collection and recording, we know that individual-level trauma is not always identified or systematically recorded or shared, particularly amongst youth justice cohorts supervised in the community. For example, there is no mandatory field on trauma and victimisation experiences in the youth justice risk assessment tool AssetPlus, and there may or may not be information about this in the more qualitative part of the assessment. In addition, there are difficulties in measuring different forms and levels of trauma. So a limitation to the analysis presented here is that a trauma-informed approach is reliant on past victimisation and trauma actually being identified in the first place. Even if it is, there are further questions to ask in terms of how such experiences are responded to, and whether sufficient gender-sensitive services are available. 
Despite the challenges, recognising past trauma and its later impact is arguably crucial in providing individualised support to girls and young women. However, there must also be a recognition of the capacity of state welfare and criminal justice institutions to re-traumatise individuals. Beyond Youth Custody (BYC) (2016) have highlighted how youth justice system involvement could effectively retraumatise vulnerable young people, particularly if they enter custody. Whilst it is 10 years since the publication of Baroness Corston's (2007) ground-breaking report on vulnerable women in the criminal justice system, the recommendation to deal with non-violent females offenders in the community wherever possible remains a crucial goal. Diversion from formal system contact, and particularly from custodial institutions, is key for dealing with the majority of women who are convicted of minor, non-violent offences. However, a two-pronged approach is required and there must also be a commitment to supporting those female care leavers already in prison.

Whilst it is not the intention of this article to conflate criminal justice system involvement with imprisonment, a limitation of the current evidence base is that much of the work on the prevalence of prior victimisation amongst those in the justice system comes from work on custody populations (e.g. see Prison Reform Trust, 2016b), hence the focus below.

\section{Imprisonment}

Estimates suggest that up to $50 \%$ of children in custody have a history of being in care (PRT, 2016a). Meanwhile, a survey of adult prisoners found that $31 \%$ of females had a history of being in care (compared to $24 \%$ of males) (Ministry of Justice, 2012). Whilst these figures may well be an underestimation of the current situation, they nevertheless demonstrate the particular concentration of care-experienced women in custody. 
On 25 November 2016 there were 3,921 women in prison in England and Wales, accounting for less than $5 \%$ of the prison population (Prison Reform Trust, 2016b). However, the vast majority of women serve very short prison sentences, reflecting the fact that most $(84 \%)$ enter prison under sentence for non-violent offences. Therefore the one-day snap-shot figure masks the high level of use of imprisonment for women in England and Wales. In the year ending June 2016, 9,204 women entered custody either on remand or under sentence (Prison Reform Trust, 2016b).

As with girls in the wider criminal justice system, the voices and experiences of women in prison have remained relatively neglected in research, despite the fact that they differ significantly from their male counterparts and often have more complex needs (Prison Reform Trust (PRT) 2016b). Evidence suggests that $53 \%$ of women in prison have experienced emotional, physical or sexual abuse (compared to $27 \%$ of men), and they are far more likely to self-harm with $46 \%$ attempting suicide at some point (compared to $21 \%$ of men) (PRT, 2016b). Imprisoned women are also more likely to be locked up further from their homes because of the lack of provision for them, which makes maintaining contact with family and friends particularly challenging.

Given that female prisoners are far more likely than men to be primary carers of young children, this also makes the prison experience significantly different for women than for men (Corston, 2007), and arguably more distressing (cf. Crewe et al, 2017). It is unknown how many of the children of imprisoned women from care will themselves be placed in the care system. However, it seems reasonable to assume that a proportion of these children will. With high levels of mental health needs amongst female prisoners, and an alarming rise in the number taking their own lives in the last year (Inquest, 2016), the vulnerability of the majority of imprisoned women is stark. And this is arguably particularly true of those who the state previously deemed to be in need of welfare, protection and support. What value is there to society of locking so many of these women up? Furthermore, as Sharpe (2016) has questioned, does the state have the right to punish those young 
people who it has previously failed to protect and support? "Indeed, for girls who have suffered victimisation without justice, punishing (through correctional intervention) their responses or adaptations to abusive situations may amount to secondary victimisation or double punishment" (Sharpe, 2016: 6).

\section{Conclusion: Towards a trauma-informed approach}

This article has highlighted the lack of research on girls in the care and criminal justice systems, whilst noting that a gender-neutral approach to policy in this area further marginalises an already vulnerable population. Girls are particularly likely to have their welfare needs redefined as risks in a risk-dominated criminal justice system, which increases the likelihood of discrimination. Despite various knowledge gaps, there is evidence to suggest that, on one hand, they may be less likely to be perceived as genuine victims, yet as looked after children they are more likely to have their own behaviour unnecessarily criminalised. Given the evidence that does exist of past trauma experienced by many females in the care and criminal justice systems, this article concludes by arguing that a trauma-informed approach (cf. Mendes et al, 2014) must underpin future work with them. However, such an approach must be developed through a gendered lens, in recognition of the fact that whilst females and males may share some similar experiences of trauma, girls may also have distinct needs, and may respond to services, and be assessed, managed and controlled by state care and control systems, in very different ways from boys. As a starting point, such an approach should be based on the following key principles.

- Listening to Girls and Young Women

Particularly important is the need to listen to females in care and ensure that those whose views are often marginalised or invisible are actually heard. Services also need to develop approaches to 
engage young women. To achieve this, practitioners should consider how to move beyond existing stereotypes that suggest females in care can be particularly difficult to work with, and likely to be more manipulative than males as well as overly-sexualised (cf. Baines \& Adler, 1994). Breaking down such damaging myths would help to lay the groundwork for greater mutual trust and respect, and increase the likelihood that the victimisation of all females is taken more seriously in the future (cf. Jay, 2014).

- Greater recognition of backgrounds of vulnerability

Secondly, there is a need for far greater recognition of the backgrounds of vulnerability that many girls and young women in care come from, as well as the potential impact of early trauma on later development and behaviour. This includes the need to recognise overlapping layers of vulnerability. For females in care, care status and gender can intertwine to create stigma and discrimination, but ethnicity and sexuality add further complexity for some which has been little explored to date. As identified above, there may be challenges for practitioners in actually identifying past trauma and victimisation in the first place. Being able to respond to such experiences with appropriate individual support represents a further hurdle.

- Acknowledging the impact of state welfare and criminal justice system failures

There is also a serious need to avoid the reliance on individual pre-care experience as the dominant official explanation for later challenging behaviour. Whilst pre-care experiences should not be ignored, a far greater understanding of how systems failures may further traumatise already vulnerable females is crucial. For example, concerns over the unnecessary criminalisation of some children in care combine with the low age of criminal responsibility in England and Wales, meaning that we bring children into the justice system at a far earlier age than many other countries, 
although this is inconsistent with the evidence on maturity and brain development (Delmage, 2013). In addition, the long-lasting consequences of a childhood criminal record have recently been highlighted by the Standing Committee for Youth Justice (see Sands, 2016) who note that the childhood criminal records system in England and Wales is one of the most punitive when compared to 15 other jurisdictions.

Once in the justice system, individuals are far more likely to return (McAra \& McVie, 2007) increasing the likelihood that they will receive a custodial sentence. Yet periods of imprisonment can themselves have a traumatising effect on individuals and make existing trauma worse (Beyond Youth Custody, 2016), with recent evidence indicating that the pains of long-term imprisonment are experienced particularly acutely by females (Crewe et al, 2017). When we combine this with the low age of leaving care and the fact that many children leaving care continue to experience compressed and accelerated transitions to independence when compared to their peers in the general population, the situation seems bleak. Yet a shift of focus from the individual to the system offers some hope.

- Diversion from formal criminal justice system contact wherever possible.

We cannot change pre-care experiences from the past, but what we can seek to change is young people's present and future circumstances, and in particular how the system responds to vulnerable young women who have experienced past trauma. Diversion from involvement in the formal criminal justice system wherever possible must be a key underlying principle, in recognition of the fact that "every interaction leaves a mark" (NPCC, 2016: 1). At the same time, there needs to be a commitment to ensuring that those females already in the justice system are not abandoned by their corporate parent, but receive the support that they may well be entitled to. In light of the various system failings identified, there are strong groups for exploring whether criminal records for 
minor offences of those in care could be wiped when young people leave the care system (cf Fitzpatrick, 2014).

- Recognition that a gender-neutral approach inevitably prioritises the male majority

Finally, despite some evidence of good practice, a gender neutral approach still dominates in relation to females in the care and criminal justice systems, and there needs to be greater recognition that this inevitably prioritises the male majority. A trauma-informed, gender-sensitive approach is required both within the care and criminal justice systems in order to ensure that the needs of those who have often experienced multiple victimisation are met. As Crewe et al (2017) have observed in their work on imprisonment, "(t)here is no necessary contradiction between recognising the multiple victimisation experienced by the majority of female prisoners, whilst also attributing them with agency, rationality and voice" (Crew et al, 2017:18). Indeed, this returns us full circle to the first key principle identified above and the importance of listening to girls and young women. Not doing so will only ensure that females continue to describe their encounters with the state "and perhaps especially, with agencies mandated to support and protect them....as sites of damage, neglect, dismissal and, above all, a lack of care" (Sharpe, 2016: 11). 


\section{References}

All Party Parliamentary Group on Women in the Penal System (APPG) (2012) Inquiry on Girls: From courts to custody, Howard League for Penal Reform, London

Baines, M. and Adler, C. (1994) 'Are girls more difficult to work with? Youth workers' perspectives in juvenile justice and related areas', Crime and Delinquency, Vol 42, No 3, pp. 467-485.

Beyond Youth Custody (2016) Trauma and Young Offenders: A review of the research and practice literature, Beyond Youth Custody.

http://www.beyondyouthcustody.net/wp-content/uploads/Trauma-and-young-offenders-a-reviewof-the-research-and-practice-literature.pdf (accessed 26 January 2017).

Collin-Vezina, D., Coleman, K., Milne, L., Sell, J. and Daigneault, I. (2011) Trauma experiences, maltreatment-related impairments and resilience among child welfare youth in residential care, International Journal of Mental Health and Addiction. Vol 9, pp. 577-589.

Corston, J. (2007) The Corston Report: A report by Baroness Jean Corston of a review of women with particular vulnerabilities in the Criminal Justice system, Home Office, London.

Crewe, B., Hulley, S. and Wright, S. (2017) 'The gendered pains of life imprisonment', British Journal of Criminology, advanced online access, January 2017 (accessed 1 February 2017)

https://academic.oup.com/bjc/article/2877142/The-Gendered-Pains-of-Life-Imprisonment

Department for Education (2016a) 'Children looked after in England (including adoption) year ending 31 March 2016', SFR 41/2016, 29 September 2016, Department for Education. 
Department for Education (2016b) Government response to Sir Martin Narey's Independent Review of Residential Care, Department for Education, December 2016

Delmage, E. (2013) 'The minimum age of criminal responsibility: A medico-legal perspective', Youth Justice, 13(2) pp. 102-110.

Fitzpatrick C (2014) Achieving justice for children in care and care leavers. Howard League for Penal Reform 'What is Justice?' working paper 14/2014.

http://howardleague.org/wp-content/uploads/2016/04/HLWP 14 2014.pdf (accessed 20 February 2017)

Fitzpatrick, C. and Williams, P. (2017) 'The neglected needs of care leavers in the criminal justice system: Practitioners' perspectives and the persistence of problem (corporate) parenting", Criminology \& Criminal Justice, Vol 17, No 2, pp 175-191.

Fitzpatrick, C., Williams, P. and Coyne, D. (2016) 'Supporting looked after children and care leavers in the criminal justice system: Emergent themes and strategies for change', Prison Service Journal, July 2016, No 226.

Her Majesty's Inspectorate of Probation (HMIP) (2014) Girls in the Criminal Justice System, Criminal Justice Joint Inspection, December 2014, HMIP, Manchester.

House of Commons Justice Committee (2013) Youth Justice: Seventh Report of Session 2012- 13. Volume I: Report, together with formal minutes, oral and written evidence. The Stationery Office, London. 
Howard League for Penal Reform (2016) Criminal Care: Children's homes and criminalising children, The Howard League for Penal Reform: London.

Howard League (2017) Programme to end the criminalisation of children in residential care: Overview paper, The Howard League for Penal Reform: London.

INQUEST (2017) Deaths of Women in Prison, England and Wales: 2007-2016.

http://www.inquest.org.uk/statistics/deaths-of-women-in-prison (accessed 4 February 2017).

Jay, A. (2014) Independent Inquiry Into Child Sexual Exploitation in Rotherham, 1997 - 2013. Report for Rotherham Metropolitan Borough Council.

Jonson-Reid, M. and Barth, R.P. (2000) 'From placement to prison: The path to adolescent incarceration from child welfare supervised foster or group care', Children and Youth Services Review, Vol 22, No 7, pp. 493-516.

McFarlane, K. (2010) From care to custody: Young women in out-of-home care in the criminal justice system, Current Issues in Criminal Justice, Vol 22, No 2, pp. 345-353.

McAra, L. and McVie, S. (2007) 'Youth justice? The impact of system contact on patterns of desistance from offending', European Journal of Criminology, Vol 4, No 3, pp. 315-345.

Mendes, P., Baidawi, S. and Snow, P. (2014) Good Practice in Reducing the Over-Representation of Care-Leavers in the Youth Justice System: Leaving Care and Youth Justice Phase Three Report. Monash University. 
Ministry of Justice (2012) Prisoners' childhood and family backgrounds, Ministry of Justice, London.

Narey, M. (2016) Residential Care in England: Report of Sir Martin Narey's independent review of children's residential care, July 2016.

National Police Chief's Council (NPCC) (2015) National Strategy for the Policing of Children and

$\begin{array}{lll}\text { Young People. } & \text { Pes }\end{array}$

http://www.npcc.police.uk/documents/edhr/2015/CYP\%20Strategy\%202015 2017 August\%202015 .pdf (accessed 25 January 2017).

O’Neill, T. (2008) 'Gender matters in residential child care' in Kendrick, A. (ed) Residential Child Care: Prospects and Challenges, Jessica Kingsley, London, pp.93-106.

Postlethwait, A.W., Barth, R.P. and Guo, S. (2010) 'Gender variation in delinquent behavior changes of child welfare-involved youth'. Children and Youth Services Review, Vol 32, No 3, pp. 318-324.

Prison Reform Trust (2016a) In Care, Out of Trouble: An independent review chaired by Lord Laming, Prison Reform Trust, London.

Prison Reform Trust (2016b) Bromley Briefings Prison Fact file: Autumn 2016, Prison Reform Trust, London.

Sharpe, G. (2012) Offending Girls: Young women and youth justice, Routledge, London. 
Sharpe, G. (2016) 'Re-imagining justice for girls: A new agenda for research', Youth Justice, Vol 16, No 1, pp. 3-17.

Shaw, J. (2016) 'Policy, practice and perceptions: Exploring the criminalisation of children's home residents in England', Youth Justice, Vol 16, No 2,pp. 147-161.

Slawson, N. (2016) 'Girls in state care and care leavers still at high risk of teenage pregnancy', The Guardian, 29 March 2016.

Sands, C. (2016) Growing up, Moving on The International Treatment of Childhood Criminal Records, Standing Committee for Youth Justice (SCYJ).

South-east protocol to reduce offending and criminalisation of children in care (2014)

http://scyi.org.uk/wpcontent/uploads/2014/04/SE protocol to reduce offending and criminalisat ion of children in care final 28 March 2014.pdf (accessed 15 January 2017)

Stanley, E. (2017) 'From Care to Custody: Trajectories of Children in Post-War New Zealand', Youth Justice, Vol 17, No 1, pp 57-72.

Staines, J. (2016) Risk, Adverse Influence and Criminalisation: Understanding the over-representation of looked after children in the youth justice system, Prison Reform Trust, London.

Taylor, Claire (2006) Young People in Care and Criminal Behaviour, Jessica Kingsley, London.

Taylor, Charlie (2016) Review of the Youth Justice System in England and Wales, Cm 9298, Ministry of Justice. 
Wilkinson, J. and Bowyer, S. (2017) The Impacts of Abuse and Neglect on Children; and Comparison of Different Placement Options Evidence review, Department for Education: Research in Practice. 